\title{
Semangat Perlawanan Musik Indie (Kasus Bali)
}

\author{
I Dewa Gede Kusuma \\ Program Magister Kajian Budaya, Universitas Udayana \\ email: dewakusuma44@yahoo.com
}

\begin{abstract}
ABSTRAK
Pengalaman atas reklamasi Pulau Serangan merupakan tolak ukur bagaimana kegagalan nyata reklamasi di wilayah Tenggara Bali. Situasi Orde Baru (ORBA) pada masa Presiden Soeharto adalah Pulau Serangan terpisah dengan gugusan Pulau Bali, lalu terjadilah penimbunan wilayah pantai hampir tiga kali luas awal Pantai Serangan. Akses ke Serangan akhirnya dapat menyatu tanpa menggunakan kapal atau boat. Masyarakat adat pasubayan di Bali selatan, berhasrat tidak ingin tertimpa persoalan serupa pengalaman terjadi di Pulau Serangan. Masyarakat di Bali selatan terlibat menolak dan melawan rencana reklamasi lewat praktik musik indie secara damai, kreatif, dan tanpa aksi anarkisme. Penelitian ini dilakukan dengan metode kualitatif dalam konteks kajian budaya kritis. Hasil penelitian menunjukkan bahwa aktivis lingkungan dan musisi indie di Bali sejak tahun 2012 semakin gelisah pascamunculnya isu rencana reklamasi Teluk Benoa. Musisi indie perlahan-lahan mengarahkan ideologi pergerakannya menolak gagasan pemerintah dan investor pengembang untuk mereklamasi Teluk Benoa seluas $838 \mathrm{Ha}$ di Tanjung Benoa, Jimbaran, Kabupaten Badung, Bali. Musik Indie memiliki kepentingan melawan dalam menyampaikan pesan sosial atas kondisi riil yang terjadi di masyarakat. Gerakan musik indie berkolaborasi bersama aktivis dan masyarakat adat dalam menyampaikan pesan-pesan perlawanan sebagai upaya melindungi lingkungan alamiah Bali di masa mendatang.
\end{abstract}

Kata kunci: musik, perlawanan, reklamasi.

\section{ABSTRACT}

The experience of Serangan Island reclamation is a benchmark for the real failure of reclamation in the Southeast of Bali. The New Order (ORBA) situation during the time of President Soeharto was a separate Serangan Island with the cluster of Bali Island, and then there was a hoarding of coastal areas almost three times the initial area of Serangan Coast. Access to Attack can eventually blend without using a boat or boat. Indigenous peoples pasubayan in southern Bali, eager not to get hit by similar problems experience occurred in Serangan Island. Communities in south Bali are involved in resisting and resisting the reclamation plan through the practice of indie music peacefully, creatively, and without anarchism. This research is conducted by qualitative method in the context of critical culture study. The results show that environmental activists and indie musicians in Bali since 2012 are getting more agitated after the emergence of the issue of the Bay of Benoa reclamation plan. Indie musicians are slowly directing the ideology of their movement to 
reject the idea of government and developer investors to reclaim the Benoa Bay area of $838 \mathrm{Ha}$ in Tanjung Benoa, Jimbaran, Badung regency, Bali. Indie music has a counter-interest in conveying the social message of the real conditions that occur in society. Indie music movements collaborate with activists and indigenous peoples in conveying resistance messages as an effort to protect Bali's natural environment in the future.

Keywords: music, resistance, reclamation.

\section{PENDAHULUAN}

Masa Orde Baru penuh dengan pembangunanisme (developmentalism). Ada pengalaman sejarah kepariwisataan Bali di mana fisik pulau Serangan di Kota Denpasar diperluas dari 111 hektar mencapai 481 hektar yang dilakukan dalam kurun waktu 1995-1998 oleh PT Bali Turtle Island Development (BTID) yang selanjutnya sebagai pemilik sah semua lahan hasil reklamasi. Dampak reklamasi adalah, ada dua tipe lahan yang terpisah yakni lahan permukiman warga Pulau Serangan dan lahan reklamasi BTID. Perubahan fisik lahan itu selain mempengaruhi kontur alam, juga mendampaki kehidupan ekonomi, dan sosialbudaya masyarakat Serangan.

Harus diakui bahwa sejak era Orde Baru hingga kini di Bali terdapat sejumlah masalah kepariwisataan di Bali yang bersinggungan dengan masalah fisik (alam, lingkungan) dan budaya kesucian yang dipercaya masyarakat serta persoalan ekonomi dan sosial-budaya terkait. Kalau kasus Serangan sudah hampir terlupakan, maka yang terakhir dan masih cukup hangat dalam perbincangan adalah kasus reklamasi Teluk Benoa.

Dalam reklamasi Teluk Benoa, selain terdapat konsistensi penolakan masyarakat adat pasubayan, kajian LPPM (Lembaga Penelitian dan Pengabdian kepada Masyarakat) Unud (Universitas Udayana) menunjukkan bahwa ide atau rencana pemanfaatan dan pengembangan kawasan perairan Teluk Benoa Provinsi Bali untuk membangun Pulau dengan teknik reklamasi, dianggap "tidak layak". Ada persoalan fisik lingkungan di samping persoalan kesucian di dalamnya meskipun alasan reklamasai: menambah ruang terbuka hijau, menata lahan di daerah pasang surut, tempat evakuasi bila terjadi bencana tsunami Bali selatan, alih fungsi lahan produktif, mengurai kemacetan, menciptakan ikon pariwisata baru, dan 
Journal of Music Science, Technology, and Industry Vol. 1 No. 1 (2018): 119- 128 E-ISSN 2622-8211

pengembangan kearifan lokal. Setelah dikaji secara akademis oleh tim LPPM Unud baik dari aspek teknis, lingkungan, sosial-budaya dan ekonomi-finansial, reklamasi tersebut dinyatakan "tidak layak".

Setelah LPPM Unud menyatakan tidak layak, perjalanan rencana reklamasi Teluk Benoa tidak langsung batal. Justru itu menjadi tugas berat Forum Rakyat Bali Tolak Reklamasi (ForBALI), masyarakat adat, dan musisi indie untuk mengawal pencabutan Perpres No. 51 tahun 2014. Aksi demonstrasi masyarakat umum telah rutin dilakukan dengan menggelar hiburan konser mini Bali Tolak Reklamasi (BTR). Pemerintah dan investor (pengembang) sering berkelit dengan mengatasnamakan "revitalisasi Teluk Benoa". Keterlibatan musisi indie menolak kebijakan pemerintah pusat dalam bentuk Perpres No. 51 tahun 2014 tentang perubahan atas Peraturan Presiden No. 45 tahun 2011 tentang Rencana Tata Ruang Kawasan Perkotaan Denpasar, Badung, Gianyar, dan Tabanan. Gerakan musisi indie tersebut bertujuan mencegah dampak buruk ditimbulkan apabila reklamasi terjadi apalagi hingga seluas $838 \mathrm{Ha}$.
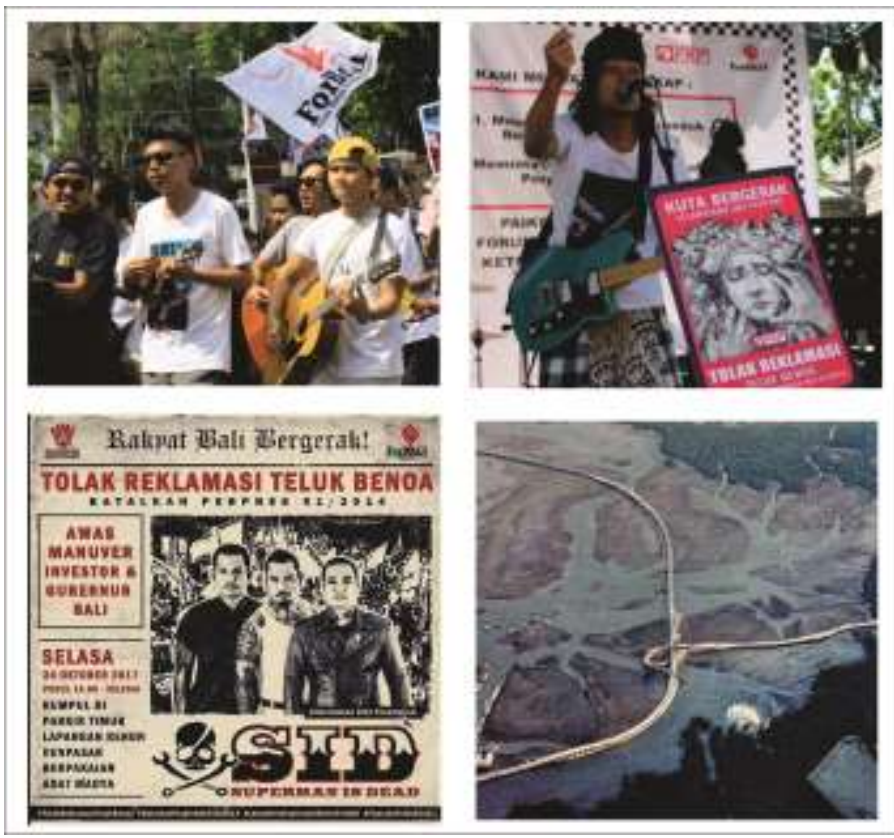

Gambar 1 Perlawanan musik ini menolak reklamasi Teluk Benoa ${ }^{1}$

\footnotetext{
${ }^{1}$ Atas kiri: NOSTRESS Band (luhde.nawalapatra.com/). Kanan: Navicula (tempo.co). Bawah kiri: pamflet SID (YouTube.com). Kanan : reklamasi Teluk Benoa di atas lintasan Toll Bali-Mandara (mnctrijayafm.com).
} 
Journal of Music Science, Technology, and Industry Vol. 1 No. 1 (2018): 119- 128 E-ISSN 2622-8211

Reklamasi dinilai masyarakat Bali menyalahi nilai-nilai religius pasubayan adat Bali. Dalam hal ini ada persoalan antara pengetahuan masyarakat lokal (local genius) dan kekuasaan di pemerintah pusat. Ketika Presiden RI keenam Susilo Bambang Yudhoyono diganti Presiden RI ketujuh Joko Widodo, Perpres No. 51 tahun 2014 belum tercabut. Foucault menggarisbawahi munculnya praktik perlawanan dari hidup sehari-hari sebagai sesuatu yang sudah selalu meletak di dalam ruang kekuasaan (Focault, 1972, 1980), khususnya rencana yang diusulkan PT TWBI, merancang megaproyek gugusan pulau-pulau reklamasi menjadi destinasi baru pariwisata. PT TWBI wajib memenuhi empat aspek di antaranya, hukum, lingkungan hidup, ekonomi, dan sosial-budaya. Namun saat ini, PT TWBI belum dapat memenuhi terkait aspek sosial budaya.

Kedua, praktik perlawanan musisi indie atas reklamasi Teluk Benoa, menunjukkan bahwa ideologi perlawanan disampaikan secara kritis. Aktivis berperan mempelopori demonstrasi dengan mengawali tindakan melawan kebijakan pemerintah melalui argumentasi dan data-data riil menyangkut reklamasi. Praktik untuk melawan gagasan investor bukan berkonotasi negatif, tetapi dengan cara mengumpulkan data riil yang dikeluarkan pemerintah dan mengacu terhadap Undang-undang sesuai aturan berlaku.

\section{METODE PENELITIAN}

Secara umum, penelitian ini merupakan bagian dari kajian budaya kritis (critical cultural studies). Kajian budaya (cultural studies) menekankan pentingnya perubahan dan representasi dari dan untuk kelompok-kelompok sosial yang terpinggirkan (Barker, 2005: 6). Dalam hal ini, kelompok yang terpinggirkan adalah kelompok-kelompok masyarakat yang menjadi korban reklamasi Teluk Benoa.

Analisis penelitian bersifat deskriptif kualitatif dan interpretatif melalui intepretasi dengan persoalan ditemui di lapangan. Data dikumpulkan tidak saja dengan studi dokumen dan dokumentasi tetapi juga dengan observasi dan wawancara. Analisis data dilakukan dengan teknik analisis data kualitatif.

Selain teori kekuasaan dan pengetahuan Foucault, teori semiotik digunakan peneliti untuk mengkaji bagaimana signifikansi praktik perlawanan masyarakat Bali 
Journal of Music Science, Technology, and Industry Vol. 1 No. 1 (2018): 119- 128 E-ISSN 2622-8211

terhadap reklamasi Teluk Benoa melalui musik indie. Semiotik adalah studi ("sains") tentang tanda-tanda dan penandaan (signifikansi) yang dikembangkan dari karya dan pemikiran Saussure (Barker, 2014: 261). Kenyataannya, kritik tidak lagi hanya dilakukan melalui aksi demonstrasi tetapi perlawanan masyarakat pasubayan adat Bali telah disampaikan melalui atribut media kreatif dan media sosial yang rutin digunakan.

\section{HASIL DAN PEMBAHASAN}

Musik indie adalah hiburan sekaligus perlawanan terhadap permasalahan sosial. Musik indie berasal dari kata "independen". Indie memiliki arti musik berlatar rasa bebas, tanpa tekanan, mandiri, dan merdeka. Indie di tengah masyarakat hadir sebagai penolakan didikte pasar.

Indie muncul di luar mainstream musik pop yang umumnya disebarluaskan industri musik. Musik ini terkait dengan kehidupan anak-anak muda. Lirik musik indie mempesona anak muda, menginspirasi, dan membalikkan posisi industri rekaman major label yang kebanyakan berorientasi dengan tema lagu-lagu jatuh cinta serta keputusaan bercinta.

Proses demonstrasi tolak reklamasi Teluk Benoa di lapangan telah menunjukkan citra musik dan musisi indie untuk menggiring dukungan ke arah gerakan tolak reklamasi Teluk Benoa. Ketokohan individu musisi indie menjadi daya tarik pendemo, khususnya pendemo dari kalangan anak muda yang selain datang berorasi mereka pun terlibat menikmati pertunjukan musik indie.

Cukup banyak band indie mengumpulkan bait-bait lagu, tetapi karya yang mereka luncurkan belum bisa seluruhnya disenangi anak muda. Sebab, pendengar di era tahun 2017 ke atas semakin cerdas menilai single yang dilantunkan band. Berbeda dengan band yang telah mempunyai nama besar seperti SID (Superman is Dead), Navicula, The Hydrant, Scared of Bums, hingga Nosstress. Mereka tinggal mempertajam kualitas lirik dan lagu perlawanan identik gerakan Bali tolak reklamasi Teluk Benoa. Data yang diperoleh dari Walhi Bali, ada 61 event konser musik Bali tolak reklamasi yang telah berlangsung dari September 2013 hingga April 2018. 
Journal of Music Science, Technology, and Industry Vol. 1 No. 1 (2018): 119- 128 E-ISSN 2622-8211

Secara praktis sebagai sumbangan bahan pemikiran Pemerintah pusat atau daerah sebagai pengambil kebijakan yang akan dikeluarkan dalam mempertimbangkan peraturan mengenai rencana reklamasi Teluk Benoa, pihak pemerintah terkait untuk dapat menjaga kealamiahan dan tradisi di lingkungan Teluk Benoa.

Rencana membuat pulau-pulau baru bersikeras dilakukan PT TWBI dengan melakukan reklamasi seluas 838 hektar. Mereka mengincar titik Teluk Benoa, sebuah wilayah yang mereka anggap sebagai wilayah tidak produktif. Teluk Benoa memang menjadi lokasi strategis karena menjadi titik temu dari tiga kawasan ikon pariwisata Bali, yaitu Sanur, Kuta, dan Nusa Dua. Teluk Benoa secara administratif juga masuk daerah Kabupaten Badung dan Denpasar, dua daerah terkaya di Bali. Tempat ini persis berada di seberang Bandara Ngurah Rai, Pelabuhan Benoa, dan kini dilewati jalan tol atas laut pertama di Bali. Tidak heran jika banyak investor yang mengincar wilayah ini untuk perkembangan bisnis (Galuh, 2017: 38).

Sebelum gejolak musisi indie melawan kebijakan reklamasi muncul ke hadapan publik. Persoalan kemunculan Perpres No. 51 tahun 2014 ini diketahui bahwa terdapat SK kedua bernomor 1727/01-B/HK/2013 yang terbit atas permohonan PT TWBI dengan isi permohonan mereklamasi di wilayah Teluk Benoa. Sedangkan, SK Pertamanya bernomor 2138/02-C/HK/2012, tentang izin dan hak pemanfaatan, pengembangan, dan pengelolaan wilayah perairan Teluk Benoa. Di mana SK pertama telah dicabut lalu digantikan dengan SK kedua 1727/01-B/HK/2013. Berbagai manuver mengulur-ulur waktu atau buying time lalu dilakukan pendukung reklamasi (investor). Menurut pemimpin adat Kelan,

"Dampak sosialnya, jika pembangunan mengacu terus di Bali selatan, maka macetnya tidak bisa dipungkiri. Di sana tempat suci (Teluk Benoa), kita Desa Adat Kelan, biasa gunakan untuk melakukan ritual agama seperti, melasti, mapekelem, serta nganyut. Dengan adanya dasar itu, maka digunakan hal itu sebagai acuan masyarakat kami untuk menolak reklamasi" (I Made Sugita, Bendesa Adat Kelan, dalam wawancara, 29 April 2018).

Melalui pesatnya globalisasi berkembang dua dasawarsa terakhir ini, terjadi di berbagai sektor ekonomi, politik, hingga sosial budaya. Ini akan mempengaruhi cara berpikir korporasi dalam memandang strategi di masyarakat. Tidak kecuali indie yang berkembang pesat. Musik indie Bali selain berkecimpung di bidang musik, juga terlibat dalam pertarungan ideologi terhadap rencana pengembang 
reklamasi berkedok revitalisasi Teluk Benoa. Musisi indie menilai reklamasi memberi dampak buruk terhadap lingkungan masyarakat di Bali selatan. Menurut seorang musisi indie,

"Musisi yang peduli, kalau dibilang musik indie saja yang membuat gerakan ini besar, itu tidak enak rasanya. Tapi, musisi yang peduli dengan lingkungan di sekitarnya. Dan kebetulan di Bali, saya rasa mayoritas musisinya benarbenar mau peduli. Tidak hanya melulu berbicara tentang hal-hal pribadi saja, tetapi tentang lingkungannya hingga isu sosial di daerahnya," (wawancara dengan vokalis dan gitaris grup band indie Nosstress, I Komang Guna Warma, diwawancara, Senin 23 April 2018).

Perlawanan tolak reklamasi Teluk Benoa, terus menerus dibombardir musisi indie dengan tujuan dibatalkannya Perpres No. 51 tahun 2014. Di ruang publik umum musisi indie selalu menyematkan semangat tolak reklamasi, bahkan hampir setiap saat baik di media sosial, atau perjumpaan mereka bersama para fans indie di beberapa daerah, tolak reklamasi Teluk Benoa menjadi topik utama disebarluaskan. Melawan rencana reklamasi menjadi perbincangan tentang perlawanan yang bukan saja soal perang fisik, melainkan sudah menyangkut ideologi bermusik. Di kalangan pemerintah dan pengembang investor, aksi BTR dianggap menghambat realisasi reklamasi Teluk Benoa, untuk dijadikan pulaupulau baru seluas $838 \mathrm{Ha}$. Begini tanggapan seorang tokoh masyarakat setempat.

"Melihat dari proses yang terjadi sekarang, masalah reklamasi Serangan kan terjadi di era Orde Baru. Kita tahu sendiri masyarakat terhadap pemerintah saat itu tidak dapat berbuat banyak, saat itu zaman rezim Soeharto. Pulau Serangan sebelum tahun 1990-an juga sudah sering mengalami abrasi yang disebabkan pengikisan oleh gelombang pesisir karena masih alami. Ketika air laut mencari keseimbangan pasang surut yang pasti alam akan ikut terkikis. Dengan adanya reklamasi di Serangan pada tahun 1995-1996 dan berakhir tahun 1998. Proses penimbunan melalui reklamasi kurang lebih berlangsung setahun" (I Wayan Patut, tokoh masyarakat Banjar Kaja Desa Serangan, Kecamatan Denpasar Selatan, dalam wawancara, 6 Juli 2018.

Praktik reklamasi dilakukan negara tetangga Indonesia, yaitu Singapura di pantai timur dengan luas mencapai 1.500 hektar. Meski reklamasi merusak ekosistem pesisir laut, rencana proyek reklamasi tetap ada di Indonesia seperti di Pantai Losari Makassar, Teluk Palu di Sulawesi Tengah, dan Teluk Jakarta.

Isu rencana reklamasi Teluk Benoa sudah muncul sejak Desember 2012. Selanjutnya mencuat ke permukaan media masa dan baru diketahui Walhi bersama 
Journal of Music Science, Technology, and Industry Vol. 1 No. 1 (2018): 119- 128 E-ISSN 2622-8211

ForBALI pada 26 Juni 2013. Diawali dengan munculnya SK bernomor 2138/02$\mathrm{C} / \mathrm{HK} / 2012$, tentang izin dan hak pemanfaatan, pengembangan, dan pengelolaan wilayah perairan di Teluk Benoa, disusul dengan penerbitan SK bernomor 1727/01B/HK/2013 terbit atas permohonan investor PT TWBI dengan isi permohonan mereklamasi di Teluk Benoa, yang akhirnya muncullah Perpres No. 51 tahun 2014 tentang perubahan atas Perpres No. 45 tahun 2011 tentang rencana tata ruang kawasan perkotaan Denpasar, Badung, Gianyar, dan Tabanan (Sarbagita).

Rencana mereklamasi Teluk Benoa baru diketahui 26 Juni 2013, saat itu pesepak bola dunia asal Portugal yang bermain di klub terkenal Real Madrid Cristiano Ronaldo datang ke Bali untuk menanam bibit mangrove bersama Presiden keenam RI Susilo Bambang Yudhoyono. Ketika penanaman bibit manggrove itulah muncul kecurigaan Walhi Bali, dan diketahuilah informasi ternyata megaproyek reklamasi tersebut telah dirancang di Teluk Benoa. Padahal PT TWBI sampai pada tahun 2018 belum menyelesaikan ijin lingkungan atau AMDAL. Pihak PT TWBI terganjal penyelesaian AMDAL akibat aspek sosial budaya, yang mana reklamasi Teluk Benoa mendapat penolakan dari seluruh lapisan masyarakat adat Bali, nongovernmental organization (NGO), seniman, dan musisi indie.

Menurut seorang pengurus Walhi Bali,

"Saat ini, pihak investor pengembang PT TWBI sedang memproses Amdalnya di Kementrian Lingkungan Hidup dan Kehutanan.Proses Amdal berlangsung sejak 2014 sampai saat ini (2018). Sedangkan, ijin lokasi itu berlaku dua tahun (2014-2016) dan dapat diperpanjang untuk dua tahun lagi (2017-2018). Artinya ijin lokasi akan berakhir 25 Agustus 2018, dan tidak dapat diperpanjang lagi. Tahun ini (Tahun 2018) adalah menjadi tahun penentuan bagi gerakan reklamasi agar dapat dibatalkan" (pengurus Dewan Daerah Walhi Bali Suriadi Darmoko, dalam wawancara, 20 Januari 2018.

Titik Teluk Benoa merupakan kawasan konservasi. Teluk Benoa berada di titik campuhan di mana hal ini terkait fenomena kesucian alam dan kepercayaan masyarakat adat Hindu Bali, serta Teluk Benoa adalah bagian lingkungan ekologi yang patut dilestarikan. Investor PT TWBI melirik peluang dan potensi lahan reklamasi $838 \mathrm{Ha}$ itu, jika berhasil direklamasi dapat meminimalisir biaya pembelian tanah dengan teknis menimbun kawasan teluk. 
Journal of Music Science, Technology, and Industry Vol. 1 No. 1 (2018): 119- 128 E-ISSN 2622-8211

Gerakan musisi indie, aktivis ForBALI, Walhi dan masyarakat dilakukan sejak tahun 2012, hingga kemunculan Perpres No. 51 tahun 2014, sampai akhir tahun 2018, pihak pemerintah pusat tetap tidak bergeming. Tanpa pembatalan atau pernyataan sikap menolak reklamasi oleh pemerintah pusat. Kawasan Teluk Benoa dianggap amat penting karena melindungi sejumlah desa adat pasubayan berada di kawasan Bali selatan dari gelombang ombak samudera. Ini karena areal Teluk Benoa dipenuhi hutan mangrove sebagai ruang terbuka hijau dan mencegah abrasi pantai.

Perubahan kontur alam terhadap rencana penimbunan Teluk Benoa, akan dirasakan masyarakat dan mempersempit ruang tangkap nelayan. Dampak dimaksud dikhawatirkan semakin parah bila megaproyek reklamasi benar diwujudkan pemerintah. Teluk Benoa dipercaya masyarakat sebagai titik campuhan suci. Kawasan diyakini umat Hindu sebagai titik temu energi niskala roh suci. Masyarakat diharapkan senantiasa merawat ekosistem mangrove dan pesisir sebagai wujud pelestarian terhadap alam Teluk Benoa.

\section{PENUTUP}

Praktik perlawanan musik indie membatalkan Perpres No. 51 tahun 2014 secara konsisten dilakukan musisi indie Bali. Musisi indie intens turun berdemonstrasi, melibatkan penggemar secara luas lewat kegembiraan bermusik, lagu tolak reklamasi, dan non anarkis. Bentuk representasi estetik musik indie terhadap Teluk Benoa menjadi nilai baik, bahwa hak demonstrasi menolak reklamasi dilakukan tertib menggunakan pakaian adat madya Bali. Signifikansi perlawanan musik indie terhadap reklamasi Teluk Benoa, agar Teluk Benoa tetap lestari tanpa ada pembangunan semacam marine park. Sebab, kondisi pembangunan fisik dan pariwisata terlanjur padat di Bali selatan.

\section{REFERENSI}

Barker, Chris. 2005. Cultural Studies, Teori dan Praktik. Bantul: Kreasi Wacana.

Barker, Chris. 2014. Kamus Kajian Budaya. Yogyakarta: PT. Kanisius. 
Journal of Music Science, Technology, and Industry Vol. 1 No. 1 (2018): 119- 128 E-ISSN 2622-8211

Foucault, Michel. 1972. The Archaelogy of Knowledge \& the Discourse on Language (terjemahan L'archeologie du Savoir). London: Tavistock Publications Limited.

Foucault, Michel. 1980. Power/Knowledge, Selected Interviews and Other Writings 1972-1977 (C Gordon, Ed.). New York: Pantheon.

Galuh, I Gusti Agung Ayu Kade. 2017. Media Sosial dan Demokrasi Tranformasi Aktivitas Media Sosial ke Gerakan Nyata Bali Tolak Reklamasi. Yogyakarta: Penerbit PolGov.

LPPM Unud. 2013. Ringkasan Laporan Studi Kelayakan Revitalisasi Teluk Benoa. Denpasar: LPPM Unud.

Walhi Bali. 2018. "Data Musisi Indie Tolak Reklamasi. Laporan Data Musisi Indie Tampil dalam Acara Tolak Reklamasi Teluk Benoa Tahun 2013-2018)". 